\title{
The Psychoanalytic Method of George Atwood
}

\author{
By Natalie Smolenski
}

2016

\section{Abstract}

In what technê, and what habitus, must a psychoanalytic practitioner be skilled in order to facilitate the healing of patients? To answer this question, this paper takes as its case study the clinical practice of George Atwood, the phenomenological psychoanalyst whose book, The Abyss of Madness, describes his work with patients embroiled in struggles with the most serious psychological disorders. Atwood's method is fundamentally emancipatory in that it seeks to help the patient liberate himself from psychological bondage to and enmeshment within the traumatic experiences and oppressive social bonds that have shaped his excruciating experiential world. The path toward this emancipation can only be based in truth, and as such, Atwood's method is predicated on the continual exercise of courage in service of "the inner truth of a life." The dedication to practice such courage through the often-overwhelming encounter with the "blood" that, according to Atwood, characterizes every healing analysis is born of what can only be called deep love. In this context, love names a set of profound inner resources the therapist brings to his own comportment and conduct, and by extension and implication the overall trajectory of the patient's life. This paper explores several specific analytic practices 
through which the love of the analyst meets and is co-translated into the subjective experience of the patient, enabling him through embodied presence, example, and guidance to re-structure the world of his experience in ways that are more open, more life-giving, and ultimately more loving to self and other.

Keywords: Psychotherapy, method, technique, symptomatology, diagnosis

Author Bio: Natalie Smolenski is a cultural anthropologist whose work draws on Husserlian phenomenology, self psychology, and relational psychoanalysis to develop a clinically-relevant account of subject formation and transformation.

\section{Introduction}

In what technê, and what habitus, must a psychoanalytic practitioner be skilled in order to facilitate the healing of patients? That is the question which this paper seeks to answer: what is it that gives a human being the capacity to treat patients as a psycho-therapist, a "healer of the soul," sought out as a professional and often paid for her efforts? To answer this question, this paper takes as its case study the clinical practice of George Atwood, the phenomenological psychoanalyst whose book, The Abyss of Madness (2012a), describes his work with patients embroiled in struggles with the most serious psychological disorders. Atwood's contention, underlying the entirety of the work, is that madness is a fundamental human possibility open to 
every person. Accordingly, even the most profound psychopathologies can be transformed in the direction of health by the impact of human understanding on areas of experience that superficially appear to be senseless. Atwood has done his life's work in the abyss, and his case histories demonstrate the healing effects of his method and person on the lives of people who had otherwise been written off as lost causes by other mental health practitioners. For this reason, his example deserves close examination.

Deeply informed by the work of his colleague, friend, and predecessor, Bernard Brandchaft, Atwood's method is fundamentally emancipatory (Brandchaft 2010), in that it seeks to help the patient liberate himself from psychological bondage to and enmeshment within the traumatic experiences and oppressive social bonds that have shaped his excruciating experiential world. Psychoanalysis does so by way of "a dialogical method for bringing ... prereflective organizing activity into awareness" (Atwood and Stolorow N.D.), which involves not only foregrounding and describing the way a patient experiences the world, but unearthing the origins of that understanding in specific (often traumatic) life events. As such, the route to emancipation can only be based in truth. Atwood's method is predicated on the continual exercise of courage in service of "the inner truth of a life" (2012a, xiv; 2012f). By approaching the truth of a patient's life, the therapist, in turn, approaches the truth of his own. 
The dedication to practice such courage through the often-overwhelming encounter with the "blood" that, according to Atwood, characterizes every healing analysis ("There Must Be Blood") is born of what can only be called deep love. Although Atwood does not write explicitly about love, he hints here and there at its centrality to any successful process of psychological healing. For instance, when referring to an autobiographical account of the treatment of a girl diagnosed with schizophrenia in the mid-20 th century, he writes, "Renee's analyst, Margarite Sechehaye, made a profound commitment to her patient and worked closely and lovingly with her over a period of many years. That is what is needed in such cases" (2012a, 105). The "love" alluded to here is a name for a set of profound inner resources the therapist brings to his own comportment and conduct, and by extension and implication the overall trajectory of the patient's life. Robert Weinstein has written of the curative power of analytic love as follows:

love is a healing force that keeps us all connected to life and to health, and ... this is the critical ingredient of all successful analysis.... I [am not] saying that it is the therapist's feelings that cure. It is the process of analysis that cures, and our professional commitment to that process, helping the patient to say and to feel everything he needs to say and to feel. Love is the glue that cements the analytic work.

As the above statement implies, love is no abstract notion, but manifests in the habitus and technê of the healer as well as the telos of his work with and on behalf of 
the patient. In what follows, I explore several specific analytic practices through which the love of the analyst meets and is co-translated into the subjective experience of the patient, enabling him through embodied presence, example, and guidance to re-structure the world of his experience in ways that are more open, more life-giving, and ultimately more loving to self and other.

The way these practices and categories of discernment are organized here is my own, although it thematically recapitulates Atwood's own observations about the analytic process. Accordingly, this paper does not seek to locate Atwood in a historical genealogy, or within past or current debates in psychoanalysis. Rather, it seeks to distill Atwood's methodological presuppositions and practices, one of the most fundamental being that psychoanalysis is a form of emancipation. For this reason, a successful analysis gives rise to cascading transformations of the many worlds surrounding the healing patient. Atwood writes:

Consider the potential then that lies within even a single instance of individual psychotherapy that works out well, as the incomparable power of human understanding is brought to bear on a life that otherwise might have unfolded as just another destructive link in the historical sequence. The chain is broken, and rather than darkness being delivered down upon one's descendants, an illumination is bequeathed as the effects of the healing are transmitted instead.... healing is contagious, radiating into the human surround and having 
repercussions that flow indefinitely into the future ("Credo and Reflections").

The successful psychoanalyst, then, is seeding love in the world. In what follows, George Atwood will be our guide to how this may be done.

\section{Diagnosis: Discernment of Illness}

How can we as therapists be shielded against the terror of being drawn into the madness and against the potential violence to ourselves of the interplay with those who are lost in chaos? What protections can there be that will not operate as well at the expense of the patient? The key lies in one thing only: the power of human understanding. We must understand annihilation states and all the signs and symptoms expressing a person's struggle with such experiences. We must know the symbols typically used to represent these states of mind, images that are often concretized or reified, i.e., treated as tangible, substantial realities. We must use our understanding then to discover responses to our patients' crises that will help them refind a personal center and feel included again in the human community. This is the work of clinical psychotherapy research, a field now on the threshold of a new age as the older ideas 
about objectified "mental illnesses" recede and a new emphasis on phenomenology arises ("Credo").

The above paragraph's summons to understand the patient begins with the not at all straightforward inquiry: What is wrong? In other words, the question of diagnosis. Although Atwood is suspicious of currently-employed diagnostic terminology for being "embedded in a Cartesian, objectifying worldview" ("Credo"), and indeed recoils from the term "diagnosis" itself (2012a, 46), he nevertheless stresses how important it is to understand the thematic nature of each patient's unique distress. Accordingly, he treats diagnosis as a complex hermeneutic task that involves interpreting the meanings of the patient's symbolic production within the hermeneutic circle of her phenomenal world (Atwood and Stolorow 1984).

Because he sees the diagnostic process as continually evolving, Atwood stresses the provisionality of the terms he uses, referring to, for instance, "so-called bipolar disorder" and "so-called schizophrenia" ("Credo", 2012a-g). Nevertheless, he sees certain patients as emblematic cases of these disorders, which are widespread due to, in his mind, the fundamental human proclivity to preserve and/or repair endangered experiences of self and vitally significant others under conditions of extreme duress. Moreover, the dual impact of psychopathological symptomatology as both reparative and destructive testifies to its etiology under conditions of trauma. Arguably, Atwood's major contribution to the field of psychopathology has been the care with which he has been able to discern strivings toward health within 
even the most apparently dysfunctional behavior. He has been able to do this by paying careful attention to the contextual meanings of symptomatology.

What is this health, then, towards which even the "sickest" patients are striving at all times-even in acts of destruction of self or others? Although Atwood never explicitly defines it, health, in his view, partakes of the following characteristics: Wholeness; emancipation; openness; full use of cognitive and emotional faculties; mutual participation in some form of human community; and a vital "ownness" of experience and purpose. ${ }^{1}$ This is not to say that such striving toward health on the part of a suffering person is at all a neat or holistic endeavor; moreover, it is the lack of skill with which health is sought that often signals psychopathology (habitually using drastic methods to achieve what for healthy people are fairly straightforward, if not presupposed, aims). One or another of these themes may prove to be a patient's overriding concern at different times-for instance, the suicide's bid for emancipation from the shackles of suffering that she does not see may be thrown off in any other way; a patient's excruciating, self-imposed social isolation that is protecting at all costs a profoundly endangered "ownness" of experience and purpose; or a pedophile's doomed search for the lost imagined wholeness of childhood through sexual union with actual children. These thematic unities point to an underlying order structuring human subjective experience-order which is a condition of possibility for both "illness" and "health."

\footnotetext{
1 "Ownness" is a characteristic of the experience of ipseity, that is, the condition of selfhood, which is disrupted under conditions of extreme psychopathology. See Parnas and Henriksen 2014.
} 


\section{The Presupposition of Order}

Human lives ... display an invariant thematic structure, once apprehended in sufficient depth.... our individual life histories leave unique signatures on our personal universes. My life exhibits such patterns, and so does everyone's. A sense of intense and sometimes thrilling satisfaction accompanies the recognition of these unifying themes, in oneself and in others, as initially disparate elements become woven together and apparent chaos gives way to crystallizing order. There is joy in the unveiling of such things. In extending the ideas on which these analyses draw to the larger field of human existence as a whole, we recognize that the themes of the individual lives we encounter belong to a network of possibilities shared by us all ("Credo").

The presupposition of order underlies the practice of all medicine-without it, there would be nothing to heal, no trajectory along which to develop, and no criteria by which to evaluate any given state of being or relationship. That said, order is in no way synonymous with any given system of social normativity. Atwood has expressed deep suspicion of psychopathological diagnostic categories because of their tendency to play into such oppressive structures of social normativity. In keeping with Atwood's method, then, this paper concentrates not on the labels given to specific "mental illnesses," but rather on the symptomatology that a skilled 
diagnostician might recognize as signs that something has gone profoundly wrong in a person's life.

\section{Symptomatology}

The question of what is symptomatic presupposes some implicit or explicit understanding of health. I've already described Atwood's understanding of health as wholeness; emancipation; openness; full use of cognitive and emotional faculties; mutual participation in some form of human community; and, most crucially, a vital "ownness" of experience and purpose. From Atwood's perspective, health is quite simple and will naturally manifest when the minimal conditions for its unfolding are present, which in his view include some form of basic human understanding, mediated by empathic attunement: "Once the space for [marginalized] events materializes ... perhaps in the patient finding someone to listen who can be a mother, they begin to reappear, along with the children to whom they happened. Eventually it all comes together and is really not all that complicated" (2012a, 113).

The simplicity and automaticity of psychological health under amenable conditions suggest a teleological striving toward it that is embedded in the structure of human constitution-much in the way physical wounds scab over, broken bones grow back together, and colds are weathered without the conscious intervention of the suffering subject. Of course, in many cases, the body's healing telos isn't sufficient to save a patient from disfiguration, permanent impairment or loss of function, or even death. In those cases, skillful medical intervention leverages and augments the 
body's natural healing capacities. The psychotherapist thus serves as a kind of emotional and imaginational prosthetic, helping the patient to open, think, feel, and behave in ways that would be extraordinarily difficult, if not impossible, on her own.

The challenge with psychological health and healing is that much of what passes as "healthy" under the conditions of local social normativity may in fact be pathogenic - which is why attention to symptomatology is a precondition for not only individual healing but also the skillful direction of social change more broadly. The premise behind the possibility of such healing and change is that the body is a more fundamental layer of human experiential engagement with the world than is commitment to any given set of social or ideological norms. Accordingly, social dysfunction manifests on the level of bodies and primal affect prior to higher-level justifications and explanations emanating from discursive and other forms of symbolic expression. The clinical challenge with this is "tiered" system of human experience is that primal bodily-affective experiences are often dissociated under the conditions of trauma and are subsequently kept at a dissociative distance through all manner and form of symptomatology—some of which can be extraordinarily abstract and conceptual, and often utterly beholden to pathogenic normative systems. The work of psychotherapy, then, involves taking the content and form of any symptom as data points contributing to an understanding of the more primary meaning that is at stake for the patient. 
What follows is a list of symptom categories that, when present, signal that some minimal conditions for healthy development have been lacking in the life of the patient. As mentioned earlier, Atwood stresses that these symptoms are just as frequently reparative dynamics on the part of a patient that has been so deeply harmed as they are entrenchments in a movement away from health. In fact, the bipolar nature of symptoms as both potentially salvific and pathogenic characterizes Atwood's descriptions of many case histories. Although he does not specify the criteria by which to discern the trajective nature of symptomatology—that is, how to tell whether the subject is healing or retrenching in illness-I will endeavor to indicate this diagnostic distinction where possible. What makes the interpretation of symptoms even more complex is that the trajectory of psychological healing is usually not linear-it is characterized by crises and regressions which signal decisive points in the trajectory of the illness, for better or worse. In what follows, we will have the opportunity to examine each class of symptoms in more detail with attention to these salient distinctions.

\section{Reification / Concretization}

Atwood writes, "Our patients in extreme distress reify their fantasies, generally in order to substantiate personal realities that have come under assault and are threatened with dissolution ("Credo")." This concretization, however, becomes lethal to the subject's capacity to understand her own experience. By denying that there is any symbolic interpretation at work in her own construction of reality, the suffering patient becomes incapable of understanding what she herself is 
experiencing - or how to exercise agency to remedy her situation. Acting on the concretizations results in (potentially violent) behavior toward self or others that, on the surface, appears unmotivated and incomprehensible-thus escalating unattuned and perhaps even violent responses from the social surround. Speaking about a patient diagnosed as bipolar and a patient diagnosed as schizophrenic (respectively), Atwood remarks:

There is a parallel between Kay's desperate purchase of the life-saving snakebite kits and Patty Duke's attempt to drive imagined foreign agents out of the White House. Remarkably, neither of these women appears to have had any awareness of such symbolic connections. So-called bipolar patients often seem to live in a world of utter concreteness, rendering subjective life strangely opaque ("Credo").

Reification and concretization both characterize delusion, which Atwood defines as "a belief, any belief, about the validity of which there can be no discussion" (2012a, 99). Speaking to an undergraduate class in 2012, he elaborated on this as follows:

So-called delusions in so-called schizophrenia-and you know I have problems with these words and all of this, but there are the beliefs that are described as delusions, there are the disasters that are described as schizophrenia-the class of ideas that I'm talking about of which this would be an instance are always accompanied by a 
feeling of absolute certainty that it's true. These are not just ideas that float in and out of your mind-that would not be a delusion, that would be an idea that floats in and out, or a fantasy-these are the truest of all true things, known with absolute certainty. That belongs to the phenomenology of the so-called delusion: it's accompanied by a sense of absolute certainty. In a way, a delusion kind of is like an extreme exaggeration of the Doctrine of Reality with a Capital R. That's the doctrine where the clinician thinks he knows what's absolutely real in the world and then can pass judgment, and other people agree with it or not. The so-called psychotic patient is that way too-even worse. Even more certain (2012g).

Concretization results when a psychic immune response shuts down higher-level cognitive capacities in order to preserve the psychic or physical survival of the organism—which may include the blunt fulfillment of relational needs. Atwood writes, "Delusions form, generally speaking, in a context of very severe threats against a person's sense of existing" (2012a, 100). In the process, the person may behave in a way that elicits a response from the surrounding social environment that entrenches her feelings of being isolated and under siege. In this way, this symptom not only short-circuits a person's full capacity to think and learn from experience, but precipitates a vicious cycle of relational suffering. Both render it diagnostic of illness. 
That said, concretization can also be the first mode in which a form of experience that has had no other opportunity to crystallize in a patient's life begins to manifest for him. Take, for instance, the case of Thomas, a case on which Atwood consulted:

My associate, a psychologist, sought my advice regarding what she thought was a sudden turn for the worse in a bipolar patient she had been treating for a very long time. This patient, a 45-year-old man whom I will call Thomas, had shown a classic manic-depressive pattern, oscillating violently between the extremes of uncontrolled euphoria and suicidal depression ... Now, however ... something else had appeared. The man informed his analyst that he, the patient, had suddenly recognized that he was in absolute control of all his analyst's thoughts. Hearing of this reported mental omnipotence, my colleague concluded her patient was sinking into a delusional state. [...]

[My colleague] told me that [her] patient's emotional life had always been strangely opaque, almost as if it did not exist. On the first occasion, near the beginning of their meetings, when asked how he was feeling, the patient had been nonplussed. He said no one had ever asked him such a question, and he did not have any idea about what his feelings were. He said he did not know what the word feelings even meant. He was familiar with the overwhelming rush of his manic states, and he knew about wanting to die. But he was a man who 
reported that there was no emotional life otherwise that could be described. He could not introspect or reflect, had no vocabulary for expressing what he experienced, and if pressed on the matter became very upset.

[My colleague] confirmed ... the idea that there had never been any talk about emotions in the patient's family, because the parents had related to the son as a purely exterior being, almost as if they were some sort of strange behaviorists. They focused on his actions, and their approval of him was strictly conditional on whether or not he met their very high standards of conduct. [...]

Keeping all of this in mind, the idea the patient evinced that he had absolute control over his analyst's thoughts could be considered an amazing breakthrough, a first form of an experience of attunement heralding the possibility of an emotional life arising that belongs to the patient and that could result in a freedom from the deadly cycles of bipolarity. [...]

[My colleague] chose instead to interpret her patient's imagined control as a wish fulfillment, counteracting the effects of their separations between sessions of the psychotherapy. Thomas rejected this idea, and ceased to speak of controlling his therapist's mind. ... 
She said that in the months following the remarkable claim of mental control, her patient had repeatedly accused her of trying to make him conform to some standard model of mental health, much as his parents had tried to mold him into an ideal child.... After a period of a year, Thomas abruptly terminated his sessions with his therapist (2012a, 26-30).

In the case recounted above, the patient's nascent capacity to be aware of emotions as they arose in real time became a reified fantasy of controlling his therapist's mind. The experience was located at several removes-the emotions were ostensibly those of an other, rather than the patient's, and the patient had absolute control over them, rather than being bewildered by and feeling subject to their intensity. Nevertheless, the concretized delusion served at least two important purposes: it solidified his relationship with his therapist, until then perhaps the first person who had ever demonstrated interest in his emotional life; and it gave him conceptual access to the domain of human interiority, heretofore something that he could not conceptualize. Unfortunately, Atwood's colleague interpreted Atwood's suggestion as an encouragement of delusional thinking, and in the resulting battle over "objective reality" between her and her patient, her opportunity to nurture his developmental progress was lost.

Bipolar Worlds and Companions (Salvific and Persecutory) 
The human capacity to both heal and destroy the self and others often becomes objectified in the form of companions-sometimes anthropomorphized, other times taking animal or yet different forms-whether in dreams or in waking life. Atwood writes, "Such idealized delusional companions often turn into persecutors, and the imaginary realm that has been found then becomes an unbearable hell" ("Credo"). In this statement, he indicates the phenomenological premise that beings always exist in a world, and that the nature of the being is inextricably tied to the nature of the world in which it exists. Atwood recounts this interconnection between person and world in the following case story:

A woman, 24 years old, was brought to a hospital by her father and mother after she had been arrested for trying to break into a wellknown country musician's home. I happened to be on the clinical staff and so met this young person. She was mute, and scarcely moving. The word "catatonia" was used by two of our psychiatrists, engaging in diagnostic deliberations at the time, but I have never thought much of such labels. I sat quietly by her side on a daily basis in the first weeks of my work with her, hoping she would eventually begin to speak to me. Finally she did, telling of a secret world in which she had lived for several years. This world was ruled by a famous country music star, and contained a number of other figures who regularly talked to her in the mornings and in the nights. They were like the chorus in a Greek tragedy. A love affair had developed between her 
and the star, conducted via telepathy, and she had been able for a long time to function in her world (she had been a part-time student in college) while dwelling much of the time in the secret realm.

Disaster came when she finally made an effort to have physical contact with her lover. The police had arrested her when she went to his actual home. The voices of the chorus, originally loving and sweet, had in the meantime turned increasingly critical and aggressive. [...]

Her emotional history, as I came to understand it in the long course of our contacts, centered around a theme of abiding loneliness. This context, unseen as such by members of her family of origin, was one in which she had accommodated herself to parental expectations and needs, becoming a child fulfilling their dreams through stellar academic achievements. The parents' marriage had at the same time been a bloody chaos of tension and hostility: repeatedly, the mother and the father had fought physically and threatened to abandon each other. She had tried, with all her might, to be a shining manifestation of hope for familial cohesion, always sensitive to her mother and father, moving back and forth between them, forever striving to make them proud and happy. 
The extremity of this young girl's commitment to pleasing her parents and forestalling the disintegration of her family began at some point to lead to a division in her subjective life: on the one side were her harmonizing accommodations; on the other was an unarticulated and yet intensifying sense of hurt and of her own abandonment. There was no real recognition or validation of her pain by anyone, and therefore nowhere to go with her emerging suffering. This was the setting, following a series of separations and other changes in her living situation, in which she found her true love during her late teen years. Listening to his songs of loss and alienation, of broken hearts and searing loneliness, she saw her own experiences set to music: she had found a twin, a soul mate whose feelings precisely mirrored her own. Appearing recurrently in her dreams and reveries, his presence suddenly one day became utterly real and she immersed herself in their shared affection, magically expressed through mental telepathy. Catastrophe occurred when she finally tried to establish physical contact with him.

I worked closely with her for many years, helping her to find words for her deep feelings of isolation and loneliness, and helping her as well to resist the siren-call of her lover and the chorus of voices associated with him. That is what is needed in such cases: patience, devotion, and understanding. I don't want to make it sound easy; it 
wasn't. There were a great many back and forth movements with respect to the secret world, and there were dangerous suicide attempts in the first years of our contacts. I suffered greatly with how close she came to ending her life. But it eventually worked out well enough. She brought herself together in gradual stages and found new ways to connect with others, expressing in her life a wonderful creative spirit (“Credo").

In this case, the bipolar world and companions in which the patient lived were concretized as voices and a living person with whom she could make physical contact. The attempt at contact reflected the patient's agentive striving to finally put an end to her abiding loneliness. In that sense, it was a profoundly reparative action. Unfortunately, because of its basis in a concretization, her action failed to have its intended effect.

However, as an unintended result, the patient found a real-life companion who helped her find new ways of connecting with living people in the world she shared with them, as opposed to the world she shared with her fantasy companions. Not only that, but she was redirected from relying on the compensatory and ameliorative functions of her fantasy world back toward the excruciating pain of her actual relational life with other human beings. As a result, the healing process involved a violent swinging back and forth between the devastation apparent in the truth of her life and the salvific fantasy of untroubled intimacy, eventually stabilizing 
in newfound presence with other living human beings on new relational terms. This obviated the need for imaginary companions and stabilized the bipolar world they inhabited.

\section{Transactional Relationships}

Of the case above, Atwood writes, "Her illness was not, from this standpoint, a pathology afflicting her entirely from within; it was a personal disaster brought on by complex transactional patterns inhering in her relationships over time to all those who were important to her, both real and imagined" ("Credo"). I suggest here that the "transactional patterns" referred to here are symptomatic of illness. This is so because transactions introduce a fundamental sense of precarity to the relationships upon which a person's—-particularly a child's—sense of security depends: if one part of the transaction is absent, the entire relationship collapses.

And with the collapse of relationship comes the collapse of world. This catastrophic collapse was reflected in the subjective life of the patient in the above case by the transformation of her chorus of voices from sweet, loving encouragement into a chorus of persecutors. The suicidal devastation she felt in the aftermath of her failed attempt to connect with her imaginary lover and in the ensuing years of healing reflected the lack of any stable relational foundation to her life; there was no enduring, unconditional connection on which she could rely. Until, that is, Dr. Atwood. Or was this relationship in fact the enduring, unconditional connection on which the patient could rely? 
Here a debate is waiting to be born: to what extent does the medical profession, structured as a transactional exchange of money for healthcare, introduce a limit to its capacity to seed healing, particularly in the psychological realm? A commonplace refrain among patients suffering from various forms of psychopathology is that "the therapist only cares because I'm paying him." Even in state-funded psychiatric hospitals in which patients do not pay for the services rendered to them, there is still the clear demarcation of the psychiatrist and psychotherapist as exercising a profession - that is, as people who earn their living by helping people with psychological disorders. Given his commitment to the profoundly relational nature of the therapeutic encounter, Atwood would likely take the feelings by patients that someone will only care for them if they are paid to do so very seriously.

The question then arises: Is even the most devoted, understanding, patient, and loving psychotherapist limited in the effects he can have on a patient's life by the fee-for-service structure of their interaction? Atwood writes that the young woman in the case recounted above eventually healed "well enough." But is that good enough for us, as healers of the soul? Is there a way for us to structure the exercise of our profession such that financial compensation isn't overdetermining the possibilities of the therapeutic process? Alternatively, unconditionality that asks nothing of the other party could be argued to be simply another form of submission, of pathological accommodation. Some in the psychotherapeutic profession have argued that financial payments combined with scheduled appointments create a 
real incentive for their patients to commit to treatment and get better. These are the questions that must be asked by responsible practitioners encountering the fact of the pathogenic nature of transactional relationships, and answers that move us toward a better set of conditions are likely not already on the table.

\section{Splitting Processes}

Atwood seems conflicted about splitting processes. In one place, he states unequivocally that "Consciousness does not and cannot split. It is not a material thing. Only material objects, like diamonds, can split. The person becomes someone for whom the incident did not take place, and nothing more" (2012a, 109). In saying this, Atwood groups splitting with the broader category of dissociation-a selfprotective reaction of distancing engaged in by a person who cannot integrate an experience he has undergone (Ibid.). Elsewhere, however, Atwood takes as seemingly axiomatic the psychopathological account of splitting given by Eugen Bleuler, author of Dementia Praecox or the Group of Schizophrenias (1911):

Bleuler proposed that the heart of what was known in his time as dementia praecox consisted in various splitting processes occurring in the mind: hence the term, schizo-phrenia. These included the disintegration of the logical associations of thought, the splitting of cognition from its associated affects, the dividing of positive and negative emotions, and the separating off of a private reality from contact with the externally real ("Credo"). 
Indeed, Atwood resonated profoundly with one of his patients' interpretations of Bleuler's thesis:

She had been told by her doctors her diagnosis was that of schizophrenia, and, confused about what this meant, studied Bleuler's derivation of the term from the Greek words for "split" and "mind." She told me a better translation, still respecting the etymology but connecting more closely to her own familiar self-experience, would be: "torn soul." I found her statement, obviously rooted in her feeling of being in pieces, to be one of the most astute things I have ever heard on this subject, and I told her so. We worked together for several decades and got along very well ("Credo").

However, Atwood fundamentally differs with Bleuler's framing presuppositions regarding the etiology of splitting as based in the biological brain, subject to an essentially deteriorating trajectory in which a fundamental restoration to health is impossible. As we have made clear, Atwood conceptualizes all psychopathology as relational in origin, including splitting processes. (In this way, he is in profound continuity with the psychoanalytic school of object relations, which redefined splitting with reference to the developmentally salient relational objects.) To that end, he describes Jung's "torn soul” as follows: “In Jung's case, the traumatic rupture of the tie to his mother contributed to a subsequent splitting of his selfhood into two 
distinct parts, what he came to call his No. 1 and No. 2 personalities" (2012a, 136137). Søren Kierkegaard undergoes a similar analysis:

One of his most famous works, Either/Or (1843), shows by its title the split in the heart of this man. The principal division addressed there is between what he designated the "aesthetic" and the "ethical." In later works, he spoke of the closely related tension between the "religious" and the "aesthetic." These dichotomies are intellectual parallels to the division within: between the part that remained bonded to his dear ones, to the eternity into which they had passed, and the part of him that engaged with the temporal world of immediacy and tried to connect with actually living human beings. If one examines how the categories relate to each other, the shadow of the earthquake separating him from his irresolvable mourning and his family members is unmistakably present. Søren Kierkegaard stood between two realms: the present world and the afterworld, and his life and work express a strange balancing act of trying to remain connected to both. Inasmuch as he could not wholly embrace anything or anyone, however, this unfortunate gentleman could really be faithful to neither (Ibid., 194-195).

It is the last sentence of this account which sums up the psychopathological nature of splitting. A split consciousness is one in which the subject is motivated in ways 
that are irreconcilable with, and often utterly opaque to, each other. Splitting is, to invoke a Biblical passage, the problem of "serving two masters": "No one can serve two masters; for a slave will either hate the one and love the other, or be devoted to the one and despise the other" (Matt. 6:24, NSRV). And in fact, the metaphor of servitude is an apt one, because splits always emerge to serve a particular function within a specific relational context. The functional benefits provided by the split may then be personified, for instance in dreams, as a spouse, in that there is a longterm relationship of devotion, or at the very least commitment, between the egoic person and the forms of consciousness on either side of a split.

The problem is that, much like the Gospel verse states, an egoic switch from one side of a split to the other results in an utter repudiation of the previously-inhabited side. Thus, the affective and behavioral manifestations of a person acting from a split consciousness is often one of utter inconsistency, if not outright betrayal of relational commitments made on one side of a split or another. The most fervent declarations and promises made on one side of a split can be utterly forgotten or vehemently denied or rejected on the other side of the split—and what was manifested on one side of a split as love is manifested on the other side as hate or indifference. This is not simply ambivalence, hypocrisy, or momentary reversal out of fear, but a structural, repeated toggling back and forth between utterly irreconcilable aims. The person suffering from splitting processes is on a trajectory to destroy, often without realizing how or why, everything she aims to achieve when in any split state of consciousness. 
The process of healing splits is a process of bringing a person's motivations into integrity with each other. The visceral force characterizing the motivations animating split forms of consciousness derives from primal survival needs which have gone traumatically unmet or from powerful affect states which have not been integrated. Therefore, the clinical work must first center on understanding what those needs and affects are and what gave rise to their traumatic encasement in split forms of consciousness, and then reimagine how those needs can be met and affects expressed in ways that align the mutually exclusive trajectories of the patient's life toward a single trajectory of health and growth. For patients who have functioned from severe splitting and a weak or nonexistent center of self throughout their lives, this integrated trajectory may be something categorically new-for others, it may be a solidification of an already-existing trajectory by transferring split loyalties to the path they are already on. Whatever the form the outcome takes in the life of the patient, the clinical goal is that of integrity.

\section{Self-Harm}

Self-harm, like other psychopathological symptoms, is directional in that it is purposeful—and potentially multi-purposed, at that. There are two main aspects to self-harm that are influential in a patient's decisions regarding how to instrumentalize it; both are always relevant, but one may be foregrounded over the other depending on what the patient is solving for. The first is the actual experience of the pain itself, while the second is the damage done to the body or mind of the 
person being harmed. For some patients, it is the experience of pain which is the most relevant aspect of the self-harm experience, while for others, it is the creation of damage to or destruction of the self that is most relevant. Again, both motivations are usually present, but the one being foregrounded offers an important indicator of the larger motivation behind the patient's symptom.

In recounting the case of Anna Smith, for example, Atwood described a young woman who was deeply at odds with herself-and whose self-harm served as an attempt to heal the split in her consciousness and return to life from a pervasive feeling of inner deadness (2012b, 2012c). Anna came to him for outpatient treatment while residing in a psychiatric hospital. The first thing she said, upon entering his office, was: "I turn into anyone I meet. You're not going to let that happen, are you?" During the conversation that ensued, the patient began to refer to Atwood as "Anna," asking her how she was doing. She recognized that something about this wasn't right, but her confusion persisted. During the first six weeks of treatment, Atwood attempted to give her a reparative experience of being in the company of another person while maintaining a sense of her own separateness. He painted and drew with Anna, had her read poetry and read her poetry in turn, and invited her to bring in her guitar and sing. So long as she was engaged in a creative process, Anna could maintain a separate identity. But as soon as unstructured conversation arose, she would fall back into profound identity confusion. 
After about the first six weeks, Anna pushed away the crayons and poems and guitar, looked Atwood in the eyes, and said, "George, hit me." "Hit me" became all she would say for the next six weeks, both in treatment with George and in the hospital where she was staying, all the while wearing an eerie, mask-like grin. She would not answer why she wanted him to hit her, and she ignored his objections to doing so. Finally, one day, Atwood said, "Today we're going to write, not talk." He brought out a couple of writing pads and magic markers. Anna wrote, "hit me," on her pad and handed the piece of paper to Atwood. He wrote back, "Why do you want me to hit you?" She put aside his piece of paper and wrote, again, "hit me." They went back and forth like this several times. Finally, Atwood wrote, "I do not want to cause you pain." She took this piece of paper and then wrote, in small letters up in the corner, "Physical pain is better than spiritual death." At that point, the method behind her madness became clear to Atwood: She was seeking out pain in order to counteract her massive feeling of inner deadness. It became clear that the false smile was part of the public persona she felt he had to maintain in order to get by in a tyrannical human social world, while beneath it her authentic self-experience was one of personal annihilation. In the case of Anna, then self-harm-whether by her own hand or someone else's—-was a plea to live.

For some of Atwood's other patients, however, the plea to be harmed was a plea to die. One woman brought a leather belt with metal studs to her treatment session one day, gave it to Atwood, and prostrated herself at his feet, pleading, "Beat me. Beat me to death. Do the one kind thing anyone's ever done for me. Kill me." This 
patient had suffered horrific abuse at the hands of her father and was reenacting the trauma in the mode of self-destruction (2012c). While she may also have desired the experience of pain, the trajectory of her self-harm enactment was one personal destruction. And indeed, many patients who practice self-harm do eventually kill themselves. Some even try to self-destruct without any pain at all, choosing methods such as carbon monoxide poisoning or overdosing on sleeping pills or pleasurable drugs. Their pain is simply intolerable, so they seek to end it once and for all.

For yet other patients, however, self-harm offers a way of balancing the urge to die with the urge to live. It offers a "release valve" for terrible, pressured negative emotions, including self-hatred, without actually threatening the subject's life or, in some cases, social relationships. For these patients, self-harm and self-preservation have coalesced and become synonymous. In some ways, this can be the most intractable form of self-harm, because its overlapping functions create a "loop" or "circuit," rendering it a compulsive addiction which the patient fiercely protects against any attempts at change (Farber).

Clinical work in cases of self-harm cannot, therefore, be effective unless it addresses the underlying motivation behind it. This discernment is crucial, and it depends on the clinician's suspension of surface-level forms of meaning-making in order to understand the experience of the human being exhibiting the symptom.

\section{Annihilation States}


The case of Anna, above, is a striking illustration of a patient in the midst of a continuous state of personal annihilation. In keeping with his commitment to the relational origins of psychopathology, Atwood describes the etiology of annihilation states as follows:

If someone feels his or her world and selfhood are being destroyed, then something has happened to produce that. Such feelings do not emerge from nothing; they come about in a human context involving and absolute catastrophe. One would need to look at [the patient's] early years, at the qualities of her relationships to caregivers ... I would expect to find a story of neglect, of rejection, of abuse, of invalidation, perhaps of exploitation. Such a state could only come about because of some truly awful things having happened (2012a, 103).

A sense of personal annihilation may take many forms, each of which is itself symptomatic. One is persistent identity confusion, as in Anna's difficulty understanding where she ended and other people began. Another is trouble attributing agency or causality—that is, who has done what, why, and how. Describing a patient with a schizophrenia diagnosis, Atwood writes, "There was an all-engulfing feeling of guilt, without definition and focus. A crime had been committed, but one had no idea what it was, and the punishment for this crime was a feeling of everlasting culpability" (Ibid.). Under such circumstances, concretization 
is often the suffering person's attempt to repair this profound tenuousness of self and world by creating firm handholds of stability. The broad variety of symptom categories to which they give rise suggests that annihilation states are at the root of a considerable amount of psychopathology:

My own view is that future phenomenological studies of patients in this range will show how these various features can be significantly understood as secondary to a sense of personal annihilation. This means that the primary disturbance would be seen in the shattering or even erasure of the experience of personal selfhood. Also central would be the dissolution of the sense of the realness of the world and the disintegration of all that we ordinarily experience as substantial and enduring. The most prominent visible symptoms of these disturbances, such as one sees in hallucinations and delusions, in this context appear as restitutive or reparative reactions, efforts to reunify all that has fallen apart and resolidify all that has melted away (“Credo").

In this, Atwood takes a view resonant with that of self psychologists, who posited "deficits of self" and the terror of psychic fragmentation as the root experiences behind psychopathology (Kohut 1971, 1977; Mollon N.D.). However, in contrast to self psychologists, Atwood's thinking evolved over the years to see annihilation states not as deficits but as positive structures of nonbeing (Orange, et al. 1997). 
Currently, however, the full distinction between a subjective deficit and a subjective structure of nonbeing has yet to be elaborated by any researcher in the field of psychopathology. Upon further investigation, the distinction may prove to be inadequate to describing the underlying relational and subjective processes at work. That is why the presupposition of diagnostic provisionality is crucial to the advancement of the field of mental health.

\section{Diagnostic Provisionality}

Throughout his work, Atwood stresses that diagnostic categories and symptomatology must be seen as the contextual, provisional discernments that they are, rather than reified states of being that can be easily compartmentalized away from others. For this reason, Atwood is adamant that there is still much to be learned about the nature of madness, and to that end he calls for a deeper investigation into patients' experience. The term he uses for this investigation is "phenomenology," writing, "How the patients so diagnosed will appear under a phenomenological lens remains to be seen, and what innovations in our approach to them will come forth are still to be defined" ("Credo").

In order for psychoanalysis to contribute to the unfolding science of understanding human subjectivity, then, the clinician must be capable of this kind of deeply empathic observation. The following section treats the kind of selfhood, or habitus, the clinician must cultivate in order to actually do the observational work that is a predicate of healing. 


\section{Habitus}

Habitus is the Latinizaiton of an Aristotelian term (hexis) that essentially means "what is had"-in his work, a state of being resulting from having acted to manifest that state. A habitus can denote literally being the possessor of some thing, or it can refer to a capacity (literally, "at-handness") of the subject that has been cultivated over time. In this account, I refer to habitus expansively as the overall state of being that characterizes the healer in the clinic and, in skillfully modulated ways, beyond.

In George Atwood's reflections on clinical practice, this habitus is characterized by what I take to be five dispositions that are essential if psychotherapy is to result in healing for the patient.

\section{Implication: Self-with-Other (Relationality)}

It is a foundational presupposition of Atwood's method that healing is a relational process, heavily contingent on the behavior and manner of the clinician. However, for many practitioners this is still a foreign proposition, so they comport themselves as people who are not with the patient in his or her struggle with illness. By contrast, Atwood stresses the importance of the clinician's awareness of his implication in the healing process that is underway and the sense of responsibility that accompanies the resulting sense of "us:" "The problem is that the clinician is implicated: what people show us depends in part on how we are responding to 
them. Human experience is always embedded in a relational context" ("Credo"). The clinician's capacity to fully own her contribution to the relational developments occurring between herself and her patient reflects the professional responsibility she undertakes for holding and directing the treatment, as well as her own stake in its successful outcome. All of this is implication of self-with-other.

Atwood's sense of personal implication with his patients is evident in a series of videos that were recorded of his lectures to undergraduate students (2012b-g). It is particularly striking in the case of Anna, recounted above, where it could accurately be said that he suffered heartbreak during the serious impasses of their early treatment (2012f). This heartbreak is reflected in the tenor of his voice, his facial expression, and his bodily comportment as he recounts the story of their work together. Being-with-someone implicates all of the tiers of human experience.

\section{Implication: Self-in-Other (Essential Likeness)}

For Atwood, madness is a possibility open to any human being. In the Prologue to The Abyss of Madness, he writes: "A central aim of this book is to erase the sharp boundary that has been drawn to separate madness from sanity, returning the phenomena of severe psychological disturbances to the circle of the humanly intelligible" (xi-xii). What this means is that there is an essential likeness between the clinician and the people he is treating-not simply in some things but in all things. This by no means implies a collapse of identity or a correspondence of 
motivation or behavior. Rather, it is to stress the maxim famously attributed to the Roman playwright Terence: "I am human, and nothing of that which is human is alien to me." That is, when encountering the experience of another human being, there is nothing that a fellow human being's empathic capacity cannot comprehend, given enough time, information, and skillful interpretation. Moreover, in this act of understanding the other, the clinician is brought closer to understanding his own experience. Atwood recalls, "The great German philosopher-historian Wilhelm Dilthey (1926) famously proclaimed that in the study of persons in the so-called human sciences, all understanding is a matter of "the rediscovery of the I in the Thou." It follows from this elegant idea, to my mind anyway, that in the discovery of the Thou, we find a mirror in which our own souls are made visible" ("Credo"). In this way, the implication of self-in-other is instrumental in strengthening and upholding the implication of self-with-other.

\section{Self-Hospitality}

Self-hospitality is an umbrella term I use to designate a subjectivity which refuses to marginalize, judge, hate, or other any aspects of its own experience, extending all the way back to the beginnings of its own life. In other words, the effective psychotherapist, while perhaps not completely "free" or healed from the traumas of her past, must unconditionally accept and welcome the self to whom those traumas happened. If she cannot, she will not be able to unconditionally welcome, and 
facilitate the healing of, the selves to whom her patients' traumas happened. Atwood puts it in the following way:

If an analyst is not on friendly terms with the child within, there is no chance for there to be successful clinical work with patients such as the one I am describing [a woman suffering from so-called dissociative identity disorder]. The world of ancient trauma simply cannot manifest itself, and if there are alters that have begun to crystallize, they will vanish in the face of the analyst's intolerance and hatred. An analyst who can bear his or her own childhood feelings, by contrast, will tend to respond maternally to any signs of such experiences in a patient, and the stage is then set for the coming forth of the trauma (2012a, 112).

In other words, human subjectivity affords a ground for experience to manifest, be seen, and be incorporated into the sense of self generated by the subject. The patient, almost by definition, cannot (yet) do this-he is suffering from an inability to see, own and integrate certain aspects of his own experience. The only therapist who can help him do so is someone who has herself done this work with regards to her own experience. If she has not, psychotherapy is destined to become a painful enactment of the blind leading the blind further and further into illness-even if the truth is expressed. As Atwood writes, "Denial systems [including dissociation] ... cannot be broken down by direct confrontations with the truth. A space for that 
truth first has to be created" (Ibid., 114). That space is created by a hospitable subjectivity.

Hospitality to self is a condition for hospitality to the other-which the other, in turn, transmutes into hospitality to self.

\section{Unconditional Commitment and Hope}

Psychotherapy is a profession in which there are never any guarantees. The precarity of the self-states with which the clinician's patients are struggling could result in countless trajectories of suffering and dysfunction as well as trajectories of healing and integration. The process of healing itself is riddled with crises, regressions, and periods that feel like stagnation, so that the direction of the treatment is often unclear. Moreover, neither clinician nor patient has privileged access to its outcome. Under these conditions of profound uncertainty, often the only thing continuing to propel the treatment forward is the unconditional commitment and hope of the therapist. This commitment and hope is not blind, but rather based in the truth that the possibility of healing remains open even under the most dire circumstances. Atwood writes,

To engage with people in the extremes of psychological disorder is to cast oneself into the chaos - it means to embark upon a journey without an outcome that is certain, often with harrowing developments along the way, always requiring a commitment that is 
absolute. Sometimes this journey eventuates in a healing and a thriving; in other instances all our efforts may fail and we are consigned then to bear witness to someone's devastation. Therein lies the suffering, in the knowledge that nothing is assured and that catastrophe is always at hand. On the other side, our commitment, being absolute, means there also is hope for healing and recovery, and there is something utterly wonderful about pursuing this hope with nothing held back. If things do not work out, and perhaps there is a suicide or some other incontrovertible disaster, we die a thousand deaths. If on the other hand a better way is found, the Phoenix rises from the ashes, and one then has the sense of having participated in the sacred ("Credo").

\section{Ethic of Service}

An ethic of service denotes two inextricably related things: 1) Continuously solving for how best to be of service to the patient; and 2) Selflessness. This ethic can only be nurtured based on the presupposition that the patient is coming to the clinician for help with a dire set of circumstances that overwhelm her existing capacities to understand and ameliorate them. The clinician is being sought out in a professional capacity precisely because she is presumed to have the ability to help. In this way, although the relationship between patient and clinician is profoundly mutual through implication, and although the clinician tailors treatment to the specific needs and cues of the patient, it is not equal in a functional sense: the clinician is 
responsible for holding and guiding the healing process, thus being of service to her patient, while the patient is in no way expected to be of service to the clinician. It is the clinician who must routinely set aside her own self-centered (here used not as a value judgment but as a descriptive statement) strivings and satisfactionsincluding any need to know better; be an authority; or gain praise, approval, or any other satisfaction from her patients-to do the precise, surgical work of determining the most important causal factors in the illness and the painful, loving work of addressing them over time.

Whenever a psychotherapist's ethic of service collapses, catastrophe for the patient ensues. Atwood recalls one example from his case literature:

The account concerns a 31-year-old woman who sought help because of paralyzing feelings of being a frightened child, lost in a world of high-powered grownups. These disruptive states stood in contrast to her external situation, one of having achieved great financial success and of having earned the respect of numbers of people who followed her leadership. She was an impressive adult by every objective criterion, but her feelings were of being a terrified little girl. [...]

She had undergone a terrible sexual exploitation, perpetrated against her by an earlier psychotherapist. The store was this: She had known, loved, and trusted a man, who had helped her during her late teen 
years with deeply buried feelings arising out of extreme neglect and abuse in her family of origin. But then, having earned her devotion over a 3-year-period, he changed the terms of their tie: It now became her responsibility to keep him sexually satisfied. He presented the new arrangement with an explanation that their sexual interaction would help her crystallize her emerging identity as a mature woman. She had absolute faith in this gentleman, who she believed had saved her life, and therefore complied. For more than a year she provided oral gratification on a regular basis, and even paid for the opportunity, because of its ostensible purpose of solidifying her flowering womanhood. Finally, when she began to express doubt and confusion, he became angry and denounced her for being too childish to appreciate the incomparable gift she was receiving. She then fled the relationship, vowing never again to depend on anyone (2012a, 9596).

By reversing the terms of who was serving whom (and in what way), this patient's therapist did incalculable damage to her already-wounded personhood. It was left to Atwood to pick up the pieces-which in itself reflected a remarkable tenacity on the part of the patient, given the way she had been exploited. Atwood writes, "Working with such patients is always difficult, because trust needs to become established; but trust has become a deadly enemy. So one goes back and forth, often for a long time; eventually though things tend to work out if there is a shared understanding of 
the storms of fear that arise" (Ibid., 97). This patient was placing her trust in Atwood's ethic of service-a responsibility he keenly felt.

The "love" described in the Introduction to this paper as a set of profound inner resources the clinician brings to his own comportment and conduct, and by extension and implication the overall trajectory of the patient's life, encompasses in one word all four of these dispositions: implication of self-with-other; implication of self-in-other; self-hospitality; unconditional commitment and hope; and an ethic of service. Where any of these are missing or compromised, the clinical work will stall; end; be less effective than it otherwise could have been; or potentially harm the patient even more grievously.

\section{Technê}

Technê is another Aristotelian term. Although often translated as "craft" or "art," for Aristotle it is more than that: it is, in effect, the putting-into-practice of scientific reason in order to bring things about in the world. The Stanford Encyclopedia of Philosophy summarizes it this way:

Technê is a disposition (hexis) that produces something by way of true reasoning; it is concerned with the bringing into existence (peri genesin) of things that could either exist or not. The principle (archê) of these things is in the one who makes them, whereas the principle of 
those things that exist by necessity or by nature is in the things themselves (Parry).

As the above definition notes, technê is not simply a series of procedures; it is the outworking of the reasoned disposition of the maker, who is the archê (principle) of the work, and as such very much contingent on his subjectivity. For these reasons, I think it is more apt to translate technê as "method," particularly in a healing practice that aspires to be scientific (although Atwood may disagree with the claim that psychotherapy should be a scientific enterprise-see Orange et al.). The muchwritten-about psychoanalytic concept of "technique," while close in meaning, lacks this subjective dimension.

In what follows, I discuss six methodological principles employed by George Atwood which together form an indispensible foundation for psychotherapeutic technê.

\section{Suspension of Normativity (Conventional Meaning-Making)}

Atwood stresses again and again that psychopathological symptoms have meaning, but this meaning is not readily discernible on the basis of conventional social understanding:

What does it really mean when we regard something someone says or does as crazy? It means that something happens-the person does something, says something, believes something, that we can't make 
any sense of. We can't find a context in which it has meaning. We can't see a method in the madness. So, in our ignorance, in giving up on the possibility of finding such a thing, we pronounce a person crazy. So the word "crazy" really means we don't understand them. It's not really saying anything positive about somebody; it's saying something negative about our understanding: that we don't possess it (2012d).

Because of the failure of conventional meanings to illuminate the logics of madness, the clinician encountering a patient must habitually suspend her presuppositions and assumptions in order to create the openings in her frame of reference by which understanding can enter. The conventional meanings that must be suspended, however, are not only those of the surrounding society or "common sense," but those of the psychotherapeutic professions themselves, whatever their theoretical orientation. As Atwood and his colleagues, Robert Stolorow and Donna Orange, point out:

One of us remembers being told by a supervisor years ago that with long experience one would no longer be surprised by patients, that the incapacity for further surprise was the mark of a mature clinician. What a loss! So many possibilities of experience for patient, analyst, and analytic couple are foreclosed by devaluing surprise and new experience. Making a routine procedure out of the analytic couch, for example, ignores the developmental importance of mutual gaze 
regulation and other forms of facial affective communication in forming possibilities of relatedness. We must, instead, retain a thoroughly exploratory attitude toward everything we do and create together in a psychoanalysis, and relentlessly seek the meanings, both individual and cocreated (Orange et al.).

\section{Empathy}

Suspending conventional meanings and leaving open the possibility of surprise is only the first step; after that, data must be collected regarding the patient's life history and particular expressions of suffering. The major instrument for this information-gathering task is the psychotherapist's empathy. Atwood describes this process as follows:

So the phenomenological perspective enjoins us to seek an answer to the question, "What's the meaning of this that I'm looking at?" Meaning, what's it's place in the world this person lives in? In order to answer that, I have to climb into that person's shoes. I have to imagine myself into their life situation. I have to construct a picture of the world as they perceive it. This can be hard to do. People can't necessarily tell you directly what they're experiencing. You have to study them. You have to kind of interrogate the situation. Ask questions. Form hypotheses. Find ways to check whether they are on 
the right track or on the wrong track. And gradually, you come to an idea about what it might be (2012d).

Empathy is a whole-body endeavor: the clinician uses the patient's facial expressions, body postures, actions, feeling-tone, words, and habits-all reflected to him by the senses of his own body-in order to form an educated guess about what the patient is experiencing and has experienced. Her body will automatically give her important clues about what her patient may be thinking and feeling, and she may make use of this data as long as she remains open and tuned in to it. Regarding the patient's self-expression, whether in words or behavior, Atwood advocates for a technique he calls "soft listening" - a form of interpretation that is metaphorical and poetic rather than literal and concrete (2012e). In this way, the essential meaning of what the patient is intending to express will not get lost in any particular form or content he may use to express it. This is an extraordinarily important contribution to the practice of psychoanalytic empathy.

Empathic data should be supplemented, however, with explicit questions about the nature and accuracy of the clinician's impressions. Empathy is not, after all, the superpower of mind-reading, but simply a mode of observation which can be more or less granular depending on the use to which it is put. Instances where the clinician's empathic data seems to be radically at odds with the patient's selfnarrative offer rich material for analysis and working through. 


\section{Introspection}

As the clinician collects empathic data about the patient before him using his body, it is inevitable that he will experience his own personal reactions to that data. This also is a rich stream of information to be analyzed. Within classical psychoanalytic theory, more extreme versions of this phenomenon, in which the analyst begins actively projecting his own psychological vulnerabilities and entanglements on the patient, have been referred to as countertransference. Whether "transferential" or not, however, the analyst's reactions to his patient are an ongoing aspect of the therapeutic encounter and at times may be the analyst's most reliable source of data about what may be going on.

To that end, Atwood advocates for jettisoning the classical stance of analytic neutrality and voicing the analyst's experience to the patient when the analyst's best judgment suggests it would further the goals of the treatment-for instance, by helping the patient understand what he or she may be reacting to. Atwood, Stolorow and Orange write:

What is an alternative stance [to Freud's classical proposition of neutrality] appropriate for the analytic situation recognized as a dyadic intersubjective system of reciprocal mutual influence, to which the organizing activities of both participants make ongoing, codetermining contributions? We ... have characterized this stance as 
one of empathic-introspective inquiry. Such inquiry seeks to illuminate the principles unconsciously organizing the patient's experience (empathy), the principles unconsciously organizing the analyst's experience (introspection), and the oscillating psychological field created by the interplay between the two (intersubjectivity). Inquiry of this kind requires continual reflection on the inevitable involvement of the analyst's own personal subjectivity and theoretical assumptions in the ongoing investigation. Unlike the posture of neutrality, the stance of empathic-introspective inquiry does not seek to avert, minimize, or disavow the impact of the analyst's psychological organization on the patient's experience. Instead, it recognizes this impact as inherent to the profoundly intersubjective nature of the analytic dialogue and seeks consciously to analyze it (43-44).

\section{Pattern Recognition}

Bernard Brandchaft, Atwood's friend and collaborator, has written at length about the "affective sequences" observable in patients suffering from various forms of psychopathology. These sequences, according to him, are indicators of "inner conflict becoming structuralized" (55) in early life and thereafter repeating continuously in a process that is "automatic, invariant, and not open to reflectionindications, I had come to recognize, of an unconscious organizing principle" (57). In 
other words, by recognizing patterns in his patients' emotional lives, Brandchaft was able to recognize cycles that were repeating, ad infinitum, traumatic formative experiences created in the context of and linked to the maintenance of relationships with early caregivers. These relationships had instilled in the child certain deeplyheld beliefs about the nature of themselves and the world which now operated, seemingly autonomously of the patient's volition, as unconscious principles organizing their world-experience.

These emotional cycles and core beliefs have behavioral correlates in routinized enactments of domination or submission, with patients often vacillating between restoring relational bonds via "pathological accommodation" to the therapist's imagined wishes, desires, or demands, and emancipating themselves from these oppressive bonds via various forms of rebellion, defiance, or attempts at domination (Brandchaft). Unfortunately, the rigid, externally-fixated nature of these enactments render the patient's ostensible goal of establishing an independent sense of self always out of reach. The survival necessity of maintaining the originary tie-with which the patient's own experience and definition of self is inextricably entwinedacts like a magical talisman within the patient's subjectivity, thwarting even sincere efforts at liberation and individuation.

Atwood, for his part, became skilled at identifying this terror of self-loss lurking at the heart of his patients' illnesses. By observing his patients' habitual behaviors and characterizations of their own experience as well as of the world around them, he 
began to understand that what was most fundamentally at stake in psychopathology was often the preservation of an experience of self in the face of imminent personal annihilation (2012a). Yet, strangely, preserving an experience of self was not always synonymous with self-preservation. More important even than remaining alive to some patients was the truth of their lives-to which they testified with their bodies when all other methods of expression had failed. In these cases, the patients' experience of self was inseparable from the truth of their lives. Some intended to kill themselves, while others were simply willing to put themselves at risk of death in order to tell their story and thereby emancipate themselves from what Brandchaft referred to as "pathological accommodation" to the logics of an oppressive relational bond. Atwood's imperative, under these circumstances, was to create space for and prompt the patient to tell her story and assert herself in the context of a safe, holding relationship with someone who cares about and believes her-thus obviating the patient's existential need for florid symptomatology.

For the skilled clinician, then, pattern recognition is inextricably tied to the interpretive task and to the nature of the clinical intervention. Atwood has said:

What does the term "meaning" itself mean? The way I think of it is just this: it's the "place" of whatever it is we're focusing on. It can be a behavior pattern; it can be a dream; it can be something a person says. It's the place of whatever it is we're focusing on in the context of the individual's whole world of personal experiencing-that's it (2012d). 
By speaking to the meaning behind the pattern, the psychotherapist addresses the most grievously wounded part of his patient's soul and engenders an experience of being seen and known in a way that may be categorically new. This novelty, in turn, produces openings which are the conditions for breakthroughs in the process of psychological healing.

\section{Discernment of Openings}

Atwood sometimes refers to "breakthroughs"-moments in which a fundamental transformation towards healing transpires in the patient's subjective experience and behavior. However, these breakthroughs are usually only noticed during or after the fact. What I mean by "openings," by contrast, are the possibilities of certain transformations occurring under obtaining conditions. Everybody is ready for something. The questions of clinical discernment are, therefore, "What is this patient ready for now?" And, "How can I facilitate his movement into and through that opening to what organically comes next?"

An extraordinarily powerful way to facilitate a patient's movement through openings is to facilitate her presence in her emotional experience-particularly the powerful negative affects she has dissociated.

The clinician who is unskilled in discerning openings will often feel like he is banging his head against a wall or a closed door. Perhaps by sheer serendipity 
something may give and a breakthrough may occur, but such groping is not something to aspire to in clinical practice-particularly since such "breakthroughs" often consist of a patient's disguised collusion with a therapist's incompetence to produce an illusion of healing ("There Must Be Blood"). Instead, an ability to discern openings is what demarcates a truly skilled clinician and is strongly tied to his diagnostic accuracy - to his ability to both precisely and expansively answer the question of what is wrong. Often simply describing the psychopathology and the circumstances which have given rise to it is enough to begin sketching out where the openings are. Then, as the clinician begins to guide the patient toward and through those openings, his hypothesis is either confirmed, disproved, or rendered more nuanced, allowing him to reciprocally refine his diagnosis and therapeutic method even further.

\section{Discernment of Closures}

Just as the ability to discern openings demarcates clinical skill, so does the ability to discern closures. There may come times when a patient, for whatever reason, shuts down and refuses to, or cannot, go any further. Under those conditions, the ability to understand what the obstacle may be and take reparative action—whether mending a therapeutic impasse; referring the patient to a different therapist; or recognizing that the patient is simply not interested in doing or able to do the work of psychotherapy and suspending or ending treatment-is a crucial aspect of the ethic of being in service to patients. Unconscionable is the clinician who, either oblivious to the closure that has occurred or choosing to ignore it, continues charging the 
patient and wasting his time in a convoluted process that goes nowhere. The case story of Thomas, recounted above, is emblematic of such psychotherapeutic cluelessness. The value of psychotherapy to a patient's life is by no means selfevident or something that should be coercively imposed. The clinician who is able to recognize when he is no longer able to be of service to a patient in a therapeutic capacity and takes appropriate action is acting in service to that patient.

\section{Conclusion: Telos}

We end our excursus into Atwood's psychoanalytic method with a discussion of the telos, or ultimate goal, of treatment. Most expansively, this goal is psychological health, but what that means in practice has been a subject of debate since the birth of the psychological professions. In the section on diagnosis, I argued that Atwood implicitly defines psychological health as wholeness; emancipation; openness; full use of cognitive and emotional faculties; mutual participation in some form of human community; and a vital "ownness" of experience and purpose. Moreover, in the Introduction, I made the claim that the ultimate aim of restoring psychological health to people for whom it has been compromised is "seeding love in the world," which is an individually- and collectively-transformative endeavor. In this section, I delve into more detail about what those characterizations may mean, based on Atwood's body of work.

Atwood delineates the aims of psychotherapy as follows: 
Can an experience be facilitated that establishes a new center, one in which compliance and rebellion are somehow integrated? Can the empathy of the clinician become a medium in which previously aborted developmental processes can be reinstated? Can a deep understanding of what is at stake for the patient finally make a constructive difference to his or her destiny in the continuing nightmare of [so-called mental illness] (“Credo"; italics mine)?

These questions position psychotherapy as, ideally, a major shift in the trajectory of a patient's life. This trajectory ceases to be defined by the imperatives of survival or self-destruction and instead aims for a centered, integrated self which becomes the stable experiential ground for a teleological, though open-ended, process of growth and development. Implicit in this individual growth and development is a new set of capacities to be with others-to implicate the self in some form of relational life, ideally founded in the love which has grounded the psychotherapy itself. What does such a healing process look like in Atwood's practice? In what follows, we examine several examples of patients coming into the health described above by examining each aspect of its definition in more detail.

\section{Centered, Integrated, Stable Self}

Over the course of his career, Atwood has worked with a number of patients who exhibited so-called dissociative identities—-that is, "alter" personalities which had 
been dissociated from the patient's default self-experience during traumatic events.

These patients exhibited an extreme form of the psychic fragmentation that characterizes so many varieties of psychopathology. One case in particular illustrated the integration process:

A 45-year-old woman called me for a consultation regarding her ongoing psychotherapy. She had been in analysis for 8 years with a well-known figure in our field. She said she was unhappy with the results of her treatment and needed advice on what to do about it. I asked her to tell me about her relationship with her analyst as well as her background. As a child she had been the victim of profound sexual abuse by her mother, who had used her relentlessly during her early years as a masturbation toy. She said that there had once been "some boys." A question came into my mind, and I decided to voice it. I asked her what the names of the boys were. She said she did not recall, and also the boys were gone and it was all a long time ago. Then another thought came to me, and again I decided to express it. I told her I thought it wasn't a very nice thing to forget a person's name. She was quiet for a moment, and then she said: "I think you are a mother. That is the whole problem in my analysis-my analyst is only a father. He always wants me to be grown-up and reasonable." 
As we spoke about her dilemma, the names of the boys began to come back to her. Finally, she told me that the boys had not disappeared; it was rather that they had gone into hiding because they believed her analyst hated children. I asked her where the boys had hidden themselves. She answered that they had hidden in her stomach. She had suffered for many years with difficult gastrointestinal symptoms.

I telephoned her analyst and advised him to speak to her about the fact that "the boys" believed he hated children. He tried to raise the issue with the patient, but was unable to avoid giving her the impression that he still hated children. He told her he wanted to know where she had gotten such a strange and incorrect notion. Their socalled treatment ended at this point. [...]

Having terminated her therapy, the patient began to see me instead... . The horrors of her early life were more completely explored, the boys were able to leave their hiding place and be recognized, and eventually, after many years, there were signs of a more complete wholeness than had been possible before.

At a certain point, she ceased to speak of boys, or of the little girls who were also included among the five alters that I met in this case. I did not ask where they had gone, knowing that they were not in hiding 
but rather that some important growth process was taking place. Finally, the patient developed a love for gardening. She planted an enclosed, beautiful flower garden arranged in a pentagon, where five different kinds of flowers would bloom simultaneously. It was implicit that the five areas of flowers corresponded to the five alters, and that the planting, nurturing, and enclosing of the garden enacted aspects of the coming together of the previously separated parts of herself. She and I never discussed this, however. Sometimes silence can be a fine and golden thing (2012a, 111-113).

In this case, it was only because Atwood was able to be hospitable toward his past selves, those which had experienced their own childhood traumas, that he was able to help the patient integrate hers. In other words, he had to be the centered, integrated, stable self the patient sought to become. And there is no question that is what she was seeking. The alternative was for "the boys" to live forever hidden in her stomach, making their presence felt by causing her unending suffering. Theirthe patient's-desire to grow together later manifested literally in her cultivation of a five-part, enclosed garden. It was a material manifestation of the wholeness she was seeking.

In another case, that of Anna, the patient began one session with the question, "Can you know my whole life" (2012f)? Unsure of what she meant, Atwood asked for clarification, only to be met with a repetition of the question. Before long, the 
question became a demand: "Know my whole life!" It finally transmuted into an expectation of Atwood's Godlike omniscience-the patient declared that Atwood knew the entirety of her experience, from birth to the present-day, on "subconscious, conscious, and super-conscious levels" (Ibid.). When he denied having such knowledge, the patient reacted with confusion, contempt, and rage.

Atwood was aware that Anna's life was utterly fragmented into disparate timelines, punctuated on either end by traumas that had overwhelmed her ability to integrate them. She associated a totally different identity with each bounded timeline, and this fragmentation caused her extraordinary suffering. Finally, Atwood asked her, "Do you want me to know your whole life so that you can be whole within yourself?" She became quiet and then replied, "You know, there may be something to that." After that, Anna's question/demand totally disappeared, and their integrative work continued (Ibid.).

It is fashionable in some circles today to make the claim that subjectivity is essentially fragmented, that dissociative identities are simply "alternative ways of experiencing the world," and that seeking or advocating for integrated selfexperience is tantamount to an authoritarian project of normative, triumphalistic self-control and control of others. It is clear from Atwood's case histories, however, that the opposite is the case. In the case of the 45-year-old woman recounted above, it was her first therapist who was constantly attempting to master and triumph over his past experience by refusing to integrate the child he had once been. It is certain 
that this child was somehow making his presence known in the therapist's lifewhether through mysterious psychosomatic symptoms, as in the case of the patient, or in seemingly out-of-control behaviors and enactments of the disavowed traumatic self-state, or both. The telos of psychotherapeutic work, then, is not to valorize these expressions of dissociative psychic fragmentation as some kind of vindication of a person's prereflective survival strategies, but to redirect that energy toward a growth process that has been devastatingly interrupted. In the process, a vital "ownness" of experience and purpose is restored to the patient—and habitual processes of derealization and dissociation fade away.

\section{Growth and Development}

What exactly is meant by "growth and development?" The metaphor of a garden in the case history above is evocative, but what would growth and development look like in the life of a person who has been integrating and centering her selfexperience? This is where "full use of cognitive and emotional faculties" becomes an end against which a patient's progress can be evaluated. For example, in our discussion of reification and concretization, we mentioned that certain higher-order faculties may be suspended as a kind of psychic immune reaction in order to protect a self-experience that has come under profound threat. However, once the bodymind's resources are no longer being constantly diverted to maintaining a survival imperative, a much broader range of functionality begins to be restored to the patient—or perhaps emerges for the first time. Things that previously were considered luxuries-for example, attention to empathic data; self-reflection; 
suspension of immediate judgment; trust of and reliance on others-begin to emerge naturally as the patient's world enlarges beyond the ongoing catastrophic apocalypse or city-under-siege which had rigidly confined her before. The patient is freed to explore aspects of the world and her own experience which previously had either seemed hopelessly off-limits or had not even entered her imagination.

\section{Emancipation}

In this way, growth and emancipation go hand in hand. By creating space for an integration of self, the psychotherapist also creates space for that self to expand and change in all sorts of exhilarating, unexpected ways. This testifies to the essential openness of the teleological process of human development-and is a criterion by which to discern the presence of normative therapeutic agendas which may be standing in the way of a patient's healing. It is also a criterion by which to discern any relationship in which a patient feels chained or confined to a limited, often catastrophic world in which growth is either a contentious battle or effectively precluded as a condition of maintaining the relational tie. Bernard Brandchaft's "emancipatory psychoanalysis," which deeply influenced Atwood, was devised precisely to respond to the extraordinary prevalence of relational systems predicated on pathological accommodation by one or more parties. He recognized that emancipation from internal and external structures of beholdenness to the demands of others was a precondition for psychological health. To that end, the therapist's responsibility is to offer the patient perhaps their first experience of a relational tie that frees-a relationship that is in no way contingent upon the 
patient's pleasing the therapist by conforming to his expectations and values (Brandchaft).

Contrary to yet another prevalent belief, this relational emancipation is not at all at odds with functioning within structures-for example, the structure of psychotherapy—though neither does it guarantee that the patient will choose to function within any given structure. Rather, it achieves what Atwood suggests is one of the aims of healing: it "establishes a new center, one in which compliance and rebellion are somehow integrated" ("Credo"). In other words, the patient no longer rebels (or rebels with much less frequency) because there is no longer anything to rebel against. The patient experiences her existence as maturely autonomous and individuated, choosing only relational ties which afford space for the continued trajective unfolding of that autonomy.

Finally, the patient becomes much more skillful in navigating situations which seem to demand compliance with a series of external exhortations. Sometimes these kinds of situations are unavoidable-for instance, in a job or at school, where rewards and progress are often contingent on a rigid set of external criteria. The healthy person is able to navigate these kinds of circumstances without becoming subject to their dysfunctional expectations, whether through self-assertion or by functioning within the structure without accepting or being beholden to its terms. 
The healthy person thus preserves his capacity to authentically think and feel under social conditions inimical to authentic thought and feeling —and in this way continues to grow indefinitely.

\section{Community}

Through the relational emancipation of psychotherapy, the patient's entire experience of community is transformed. Rather than carrying the implicit demands of transactional relationships (which, as we have seen above, are pathogenic)— including compliance, falsehood, competition, domination, or submission-the patient experiences a relationship in which neither he nor the therapist is crassly instrumentalized as part of a bid to meet survival needs or secure advantages. In other words, although the patient no doubt uses the therapist as an emotional, cognitive, and imaginal prosthetic, he experiences that this use is provisional and trajective towards a time in which it will no longer be needed—and that the therapist will continue to hold him in warm regard and be interested in him as a person once this healing has occurred. In other words, despite the drawbacks of a transactional fee-for-service model which we have invoked above, there is nevertheless significant room within such a structure for a patient to experience her therapist's unconditional commitment to her person and healing.

Once had, such an experience cannot be un-had; it is sedimented forever in the patient's body-mind as a reality and can be drawn upon again in any future circumstances. It may inspire revolutions in the patient's personal life-the end of 
or drastic distancing from relationships with parents, friends, or romantic partners that show no prospect of evolving beyond a transactional model, and the instantiation of new relationships based on the essential freedom of both parties and their mutual intention to be present in the relationship.

This is what is meant by "mutual participation in some form of human community." It could be that the possibilities for such mutuality are confined to one or two people in the patient's life—but this in itself is revolutionary. For other patients, their personal transformation may have ripple effects on entire family and community systems. In this way, love has been seeded in the world—-the ultimate aim of psychotherapeutic work. Speaking of Grace, one of his early patients who had been diagnosed with schizophrenia and suffered from extreme religious delusions, Atwood writes,

Once I established the omnipotent plan I had for her [to simply continue to work with Atwood to get better], I didn't have to do much of anything other than remain emotionally available. I watched her in the years afterward come into her own as her initial extreme dependence on our frequent contacts gradually diminished. I also saw her contend with the awful legacy of her father's decision to end his life. She spoke to me and to her family members at great length regarding her sadness and furious anger with him for choosing to kill himself. [...] 
I can say she was a joy to her family and friends. She loved animals and was instrumental in rescuing a great many dogs and cats. She remained a deeply religious Catholic, attending mass almost every day. This world would be a better place if there were more such people (2012a, 11).

\section{Love}

Robert Weinstein writes,

When we finished the analysis, Melanie wrote to me the following:

Working with you has led me to formulate for myself what I find to be a comforting, encouraging, unconditionally loving inner image. I refer to this image as my own personal "loving new mother." This image helps me to cope with the various demands of daily living, the natural losses and disappointments that we all must live through and with, and helps me keep courage as I continue to pursue living life from a positive, rather than a victimized outlook and stance. Bob, I believe therapy saved my life! 
This note describes the self-hospitality with which a former patient is now able to live her life thanks to the unconditionally implicated, hospitable, and hopeful presence of a healer who was in service to her throughout the course of her treatment. As a result of this inner hospitality, Melanie interrupted the process of self-victimization which had trapped and confined her, replacing it with a ground of inner love which opened her up to new possibilities-including a loving relationship with a new romantic partner. This is transformation.

And this transformation happens not only for the patient, but for the therapist as well. Atwood writes, "Psychotherapy is not a procedure performed upon one person by another; it is a dialogue between personal universes, and it transforms both. Our field has not caught up to this idea, but the time is coming in which it will be regarded as axiomatic" ("Credo"). With each relational transformation the therapist is able to instantiate with a patient, his own experiential world expands and opens in ways that perhaps he could not have previously imagined. This expansion and opening is, in turn, looped back into the family and community systems he inhabits.

What this ongoing reciprocity suggests is that health is not an end state but an everevolving trajectory, and "healer" is both a transitive and intransitive word-it describes both the one who heals another and one who is herself healing. This is very different from stating that people are all essentially broken or "messed up" and that there is no final remedy for such a state of affairs. No brokenness needs to be permanent; there is no experience which cannot be held and transformed, with 
time, by a ground of love. There may not be any guarantees that it will, but the possibility is always there-the basis for the unconditional hope that characterizes the habitus of a healer of the soul.

The infinite task is never a futile one. There is no limit to who we may become. The psychotherapist is an embodiment of this structure of possibility in the life of her patients.

\section{Bibliography}

Aristotle. “Nicomachean Ethics." In The Basic Works of Aristotle, pp. 935-1112. Edited by Richard McKeon. New York: The Modern Library.

Atwood, George E. (2012a) The Abyss of Madness. New York: Routledge.

---. (2012b) “George Atwood Abnormal Psychology - Lecture 1 Part

1." January 31. https://www.youtube.com/watch?v=YA5kiKDOLeo.

---. (2012c) “George Atwood Abnormal Psychology - Lecture 1 Part

2." January 31. https://www.youtube.com/watch?v=_QYMsdSepFA.

---. (2012d) “George Atwood Abnormal Psychology - Lecture 2 Part 
1." February 2. https://www.youtube.com/watch?v=03JBsMQa-FQ.

---. (2012e) “George Atwood Abnormal Psychology - Lecture 9 Part

1." March 3. http://www.youtube.com/watch?v=fpGZUru6QZs.

---. (2012f) “George Atwood Abnormal Psychology - Lecture 11 Part 1.”

March 3. http://www.youtube.com/watch?v=QxvXwYqMAKY.

---. (2012g) “George Atwood Abnormal Psychology - Lecture 13 Part 1."

March 3. http://www.youtube.com/watch?v=sEUD5dacUTw.

---. (n.d.) “Credo and Reflections.” Accessed Dec. 5, 2015.

http://www.georgeatwood.com/credo-and-reflections.html.

---. (n.d.) “There Must Be Blood.” Accessed Dec. 5, 2015.

http://www.georgeatwood.com/there-must-be-blood.html.

Atwood, George E. and Robert Stolorow. (n.d.) "Legacies of a Golden Age: A Memoir of a Collaboration." http://www.georgeatwood.com/legacies-of-the-goldenage-a-memoir-of-a-collaboration.html.

Brandchaft, Bernard. (2010) Towards an Emancipatory Psychoanalysis. New York: Routledge. 
Farber, Sharon. (2006) "The Inner Predator: Trauma and Dissociation in Bodily SelfHarm." New Orleans APA Panel, "Trauma: Obvious and Hidden: Possibilities for Treatment," August 10. Accessed December 19, 2015. http://www.apadivisions.org/division-39/sections/childhood/farber.pdf.

Kohut, Heinz. (1971) The Analysis of the Self: A Systematic Approach to the Psychoanalytic Treatment of Narcissistic Personality Disorders. Chicago: University of Chicago Press.

Kohut, Heinz. (1977) The Restoration of the Self. Chicago: University of Chicago Press.

Mollon, Phil. (N.D.) “Releasing the Unknown Self.” Accessed Aug. 25, 2013. http://www.selfpsychologypsychoanalysis.org/mollon.shtml.

Orange, Donna, George Atwood and Robert Stolorow. (1997) Working Intersubjectively: Contextualism in Psychoanalytic Practice. Hillsdale, NJ: The Analytic Press.

Parnas, Josef, and Mads Gram Henriksen. (2014) “Disordered Self in the Schizophrenia Spectrum: A Clinical and Research Perspective." Harvard Review of Psychiatry 22(5): 1-14. 
Parry, Richard. (2014) "Episteme and Techne." The Stanford Encyclopedia of Philosophy. Edited by Edward N. Zalta. (Fall) http://plato.stanford.edu/archives/fall2014/entries/episteme-techne.

Weinstein, Robert. (2007) “What Heals in Psychoanalysis?” Psychoanalytic Inquiry 27(3): 302-309. 